\title{
Tandem Mass Spectrometry of Trimethylsilyl-Terminated Poly (Dimethylsiloxane) Ammonium Adducts Generated by Electrospray Ionization
}

\author{
Thierry Fouquet, ${ }^{1,2}$ Stéphane Humbel, ${ }^{3}$ Laurence Charles $^{1}$ \\ ${ }^{1}$ Universités Aix-Marseille I, II \& III-CNRS, UMR 6264, Laboratoire Chimie Provence, Spectrométries Appliquées à la \\ Chimie Structurale, Campus Saint-Jérôme, Marseille, France \\ ${ }^{2}$ Department of Advanced Materials and Structures, Centre de Recherche Public Henri Tudor (CRPHT), Esch sur Alzette, \\ Luxembourg \\ ${ }^{3}$ Aix-Marseille Université-CNRS, UMR 6263, Institut des Sciences Moléculaires de Marseille, Chimie Théorique et \\ Mécanismes, Marseille, France
}

\begin{abstract}
Ammonium adducts of trimethylsilyl-terminated poly(dimethylsiloxane) $\left(\mathrm{CH}_{3}-\mathrm{PDMS}\right)$ produced by electrospray ionization were submitted to collision induced dissociation and revealed a particular MS/MS behavior: the same three main product ions at $m / z 221,295$, and 369 were always generated in very similar relative abundances regardless of the size of the precursor ion. Combining accurate mass measurements and ab initio calculation allowed very stable cyclic geometries to be obtained for these ionic species. Dissociation mechanisms were proposed to account for the three targeted ions to be readily generated in a two-step or a three-step reaction from any $\mathrm{CH}_{3}-\mathrm{PDMS}$ ammonium adducts. A second set of three product ions was also observed with low abundance at $\mathrm{m} / \mathrm{z} 207,281$, and 355 , which were shown in $\mathrm{MS}^{3}$ experiments to be formed in secondary reactions. An alternative dissociation process was shown to consist of a concerted elimination of ammonia and methane and the need for a methyl of an end-group to be involved in the released methane molecule would account for this reaction to mainly proceed from the smallest precursor ions.
\end{abstract}

Key words: Synthetic polymers, Tandem mass spectrometry, PDMS, Ammonium adducts, Dissociation pathways, Ab initio calculation

\section{Introduction}

$\mathrm{U}$ sing soft methods such as electrospray ionization (ESI) or matrix-assisted laser desorption/ionization (MALDI) to produce intact oligomer adducts in the gas phase, mass

Electronic supplementary material The online version of this article (doi:10.1007/s13361-010-0073-9) contains supplementary material, which is available to authorized users.

Correspondence to: Laurence Charles; e-mail: laurence.charles@univ-provence.fr spectrometry provides a whole set of very informative data for the analysis of synthetic polymers. A singlestage mass spectrum can readily reveal the size of repeat units and average molecular weights and, in case the polymer synthesis is clearly understood, it is also sufficient to confirm the sum of the end-group masses, and hence the polymerization degree. However, for each end-group to be individually mass-characterized, tandem mass spectrometry (MS/MS) is mandatory. Indeed, in most cases, major dissociation reactions usually involve backbone cleavages yielding product ions containing 
either the initiating or the terminating group. MS/MS data of synthetic polymers, most commonly obtained in collision induced dissociation (CID) conditions, should then be analyzed with regards to fragmentation rules established for the targeted polymer family. A very recent article by Wesdemiotis et al. has reviewed fragmentation pathways of diverse polymer ions, including polystyrenes, poly(2-vinylpyridine), polyacrylates, poly(vinyl acetate), polyethers, and poly(dimethylsiloxane) [1].

In some cases, however, MS/MS experiments do not allow end-group analysis because polymer ion dissociation mainly proceeds via reactions involving pendant groups, such as for sodiated poly(methacrylic acid) [2], deprotonated poly(methacrylic acid) [3], or protonated poly(methyl methacrylate) [4]. The choice of the cation to be adducted to polymer molecules was also shown to have a great impact in the production of informative fragment ions under CID conditions. For example, while dissociation of protonated poly(methyl methacrylate) (PMMA) was shown to proceed via charge-induced eliminations of methanol from the pendant ester groups [4], alkali-cationized PMMA mainly dissociates to yield low-mass radical ions carrying one of the original chain ends, according to charge-remote mechanisms [5-8]. Within the same class of metals, the nature of the adducted cation can also influence MS/MS results, as shown in the case of poly(ethylene glycol) for which dissociation of lithiated molecules generates polymeric product ions after internal backbone cleavages or rearrangements, whereas a bare alkali cation was often the only reported product ion arising from dissociation of sodium or potassium adducts [9-13].

The case of poly(dimethylsiloxane) (PDMS) is even more puzzling. Providing the adducted cation has been carefully selected and although ion activation induces inchain bond cleavages, the fragmentation chemistry of PDMS ions also depends on the nature of the end-groups [1]. Considering lithiated molecules produced by electrospray, trimethylsilyl-terminated PDMS oligomers were reported to expel only one neutral monomer unit [14], while CID of $\alpha, \omega$-dihydroxy PDMS was shown to give rise to two major product ion distributions after truncation of the chain [1] and $\alpha, \omega$-bis(3-carboxypropyl)- or $\alpha, \omega$-bis(3-aminopropyl)-PDMS dissociate primarily via intramolecular nucleophilic substitutions at the end-groups [15]. Nevertheless, considering a given polymer family, CID spectra usually display peak series in which the number and/or the $\mathrm{m} / \mathrm{z}$ ratio of product ions increase with the size of the polymeric precursor ion. In contrast, we will show here that CID experiments performed on ammonium adducts of trimethylsilyl-terminated PDMS produce the same MS/MS spectra regardless of the number of monomer units in the precursor ion. Dissociation mechanisms supported by ab initio calculation could be proposed to account for the particular unimolecular fragmentation of these PDMS adducts.

\section{Experimental}

\section{Chemicals}

Methanol was purchased from SDS (Peypin, France) while tetrahydrofuran (THF) was from Riëdel-de Haen (Seelze, Germany). Trimethylsilyl-terminated poly(dimethylsiloxane) $\left(M_{\mathrm{w}} 1600\right.$ g.mol $\left.{ }^{-1}\right)$ was purchased from PSS (Mainz, Germany). Ammonium acetate was from Sigma Aldrich (St. Louis, MO, USA). The PDMS polymer was first dissolved in THF and further diluted using methanolic salt $(3 \mathrm{mM})$ solution to a final $10 \mu \mathrm{g} \cdot \mathrm{mL}^{-1}$ concentration.

\section{Mass Spectrometry}

High resolution MS and MS/MS experiments were performed using a QStar Elite mass spectrometer (Applied Biosystems SCIEX, Concord, ON, Canada) equipped with an electrospray ionization source operated in the positive mode. The capillary voltage was set at $+5500 \mathrm{~V}$ and the cone voltage at $+70 \mathrm{~V}$. In this hybrid instrument, ions were measured using an orthogonal acceleration time-of-flight (oa-TOF) mass analyzer. A quadrupole was used for selection of precursor ions to be further submitted to collision-induced dissociation (CID) in MS/MS experiments. In MS, accurate mass measurements were performed using two reference ions from a poly(ethylene glycol) internal standard, according to a procedure described elsewhere [16]. The precursor ion was used as the reference for accurate measurements of product ions in MS/MS spectra. $\mathrm{MS}^{3}$ experiments were performed using a 3200 Q-TRAP mass spectrometer (Applied Biosystems SCIEX), equipped with an electrospray ionization source operated in the positive mode. The capillary voltage was set at $+5500 \mathrm{~V}$ and the cone voltage at $+70 \mathrm{~V}$. Primary precursor ions generated in the ion source were selected in the quadrupole analyzer and submitted to CID in a collision cell. Secondary precursor ions produced during collisions were selected and then fragmented in a linear ion trap. In both instruments, air was used as the nebulizing gas (10 psi) while nitrogen was used as the curtain gas (20 psi) as well as the collision gas. Collision energy was set according to the experiments. Instrument control, data acquisition and data processing of all experiments were achieved using Analyst software (QS 2.0 and 1.4.1 for the QqTOF and the QqTrap instruments, respectively) provided by Applied Biosystems. Sample solutions were introduced in the ionization source at a $5 \mu \mathrm{L} \cdot \mathrm{min}^{-1}$ flow rate using a syringe pump.

\section{Computational Details}

Geometry optimizations were performed using the hybrid B3LYP density functional theory (DFT) approach as implemented in Gaussian 03 [17]. The functional includes the three-parameter Becke exchange functional [18] and the LYP correlation functional [19]. This type of approach is reputedly robust against the choice of the basis set [20], 
although in some instances differences have been documented [21, 22]. We used here a moderate-size basis set, the standard $6-31 \mathrm{G}(\mathrm{d})[23,24]$, which usually gives relevant geometries and energies in such closed shell systems for geometrical optimizations of fragment ions. An extended basis set, $6-311 \mathrm{G}(2 \mathrm{~d}, \mathrm{p})[25,26]$ was also used for both fragmentation pathway energetic costs and some activation barrier evaluations.

\section{Results and Discussion}

\section{ESI-MS/MS of Trimethylsilyl-Terminated PDMS Ammonium Adducts}

The ESI mass spectrum of the studied trimethylsilylterminated PDMS (further noted $\mathrm{CH}_{3}$-PDMS) displayed a distribution of intense ammonium adducts of PDMS oligomers, with $n$ ranging from 5 to 22 (Supplemental Figure S1). Very similar CID spectra were surprisingly obtained from all precursor ions, regardless of their polymerization degree. As exemplified by MS/MS spectra of the 7-mer $\left(\mathrm{CH}_{3}-\mathrm{PDMS}_{7}\right)$ and the 21-mer $\left(\mathrm{CH}_{3}-\mathrm{PDMS}_{21}\right)$ ammonium adducts recorded at the same center-of-mass collision energy $\left(\mathrm{E}_{\mathrm{CM}}=0.91 \mathrm{eV}\right)$, three main product ions were detected with similar relative abundance at $\mathrm{m} / \mathrm{z} 221,295$, and 369 (Figure 1). These three ions belong to the series annotated $\left(\mathrm{R}_{\mathrm{n}}+73\right)^{+}$by Mayer et al. [14], with $\mathrm{R}=\mathrm{C}_{2} \mathrm{H}_{6} \mathrm{OSi}$, a dimethylsiloxyl (DMS) unit, and $n=2-4$. Although some higher congeners in this series could be observed with low abundance in the CID spectrum of the 7-mer $(\mathrm{m} / z 443$ and 517 in Figure 1a), their abundance drastically decreased or they were no longer detected as the size of the precursor ion increased (Figure 1b). In addition to this main distribution, Mayer et al. reported a $\left(\mathrm{R}_{\mathrm{n}}+58\right)^{+}$ion series to be formed upon the release of a methyl radical from $\left(R_{n}+73\right)^{+}$ions [14]. Although our experiments were conducted in the same laboratory frame energy range $(0-80 \mathrm{eV})$ as compared to Mayer's study, this ion series was not detected in our case. In contrast, a new $\left(\mathrm{R}_{\mathrm{n}}+59\right)^{+}$series (with $n=2-4$ and annotated with stars in Figure 1) was observed in the low $\mathrm{m} / \mathrm{z}$ range of the CID spectra, which intensity increased with the size of the precursor ion. The smallest size precursor ions (up to $n=11$ ) were also observed to eliminate ammonia and methane, as evidenced for $\left[\mathrm{CH}_{3}-\mathrm{PDMS}_{7}+\mathrm{NH}_{4}\right]^{+}$in the inset of Figure 1a by the peaks observed at $\mathrm{m} / z 607.2$ and 591.2.

The breakdown curves established for the 9-mer precursor ion at $\mathrm{m} / \mathrm{z} 772$ (Figure 2) are similar to those reported by Mayer et al. for PDMS ammonium adducts [14], although
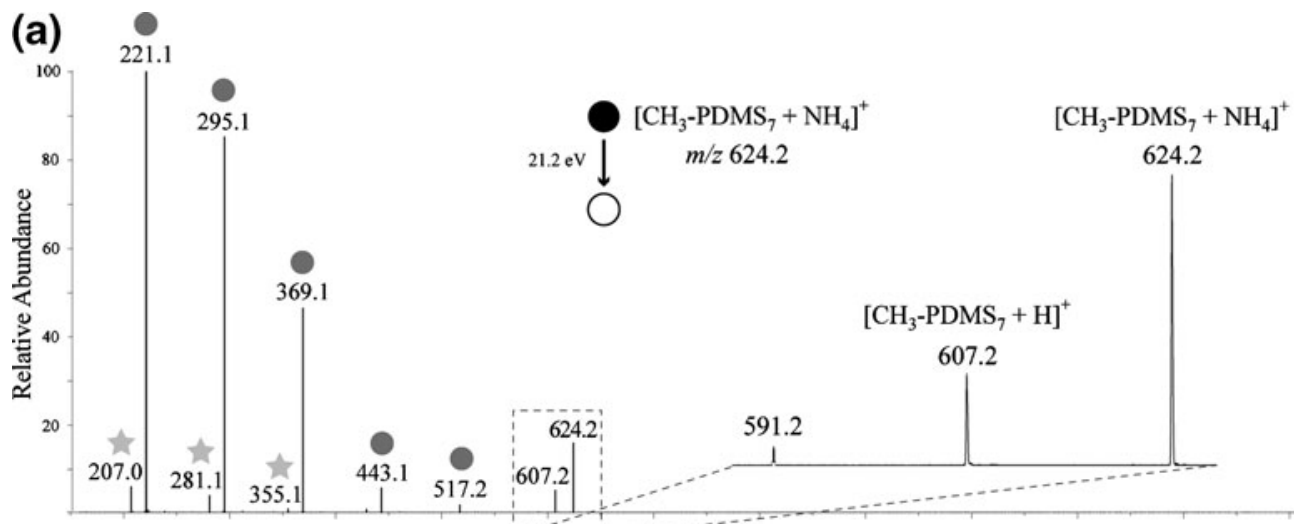
(n) 


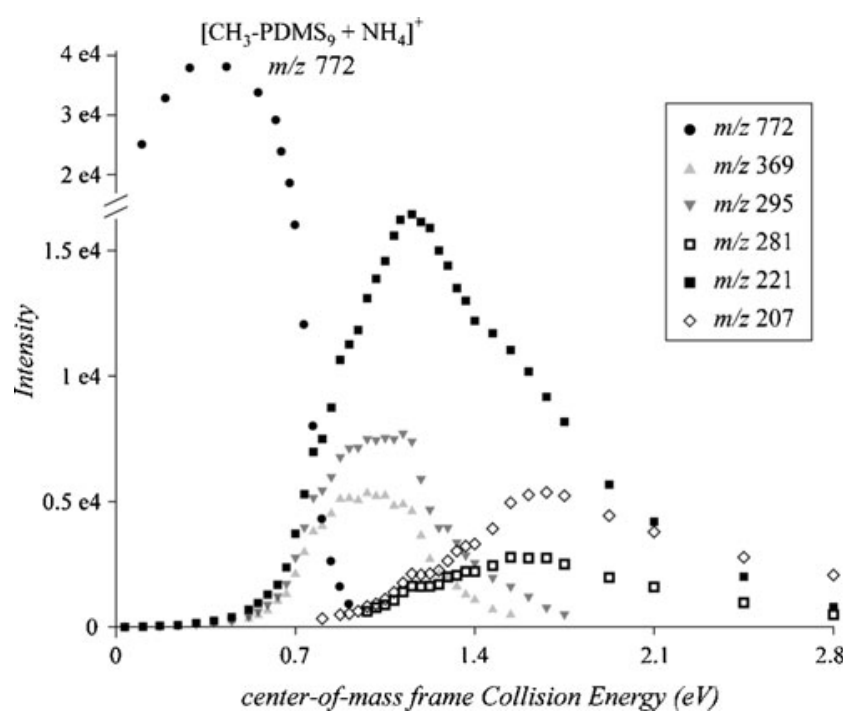

Figure 2. Breakdown curves of $m / z 772$ showing the relative abundance of $\left(R_{n}+73\right)^{+}$product ions $(\mathrm{m} / \mathrm{z} 369,295$, and 221) and $\left(R_{n}+59\right)^{+}$product ions $(\mathrm{m} / \mathrm{z} 281$ and 207$)$ as a function of collision energy (center-of-mass frame)

the appearance energy thresholds of $\left(\mathrm{R}_{\mathrm{n}}+73\right)^{+}$ions were lower in our case compared with Mayer's (about $0.4 \mathrm{eV}$ versus $0.6 \mathrm{eV}$, center-of-mass frame). Data from Figure 2 also suggest that the three main product ions in the $\left(\mathrm{R}_{\mathrm{n}}+73\right)^{+}$ series arose from competitive processes, rather than from successive reactions consisting of DMS unit elimination. Indeed, these $m / z 369,295$, and 221 product ions were all generated from about the same energy threshold and variation of their intensity as a function of collision energy displayed the same trend. In contrast, ions of the $\left(\mathrm{R}_{\mathrm{n}}+59\right)^{+}$series $(\mathrm{m} / \mathrm{z} 281$ and 207 in Figure 2) would be produced in secondary dissociation reactions, since their abundance was shown to increase from CID conditions which induced the depletion of $\left(R_{n}+73\right)^{+}$ion series. Signals obtained for the third ion of the $\left(R_{n}+59\right)^{+}$series at $m / z 355$ followed the same trend but were not reported in Figure 2 due to their very low intensity. Increase in the collision energy did not generate any new product ions but slightly modified peak relative intensity, consistently with the hypothesis of successive dissociations: the intensity of peaks at $\mathrm{m} / \mathrm{z} 369$ and 295 (main series) decreased while that of $\mathrm{m} / \mathrm{z} 281$ and 207 (secondary series) was enhanced.

The $\left(\mathrm{R}_{\mathrm{n}}+58\right)^{+}$fragment series was reported by Mayer to be formed sequentially from $\left(\mathrm{R}_{\mathrm{n}}+73\right)^{+}$ions, after a methyl radical loss occurring from about a $1.2 \mathrm{eV}$ collision energy (center-of-mass frame) [14]. In our study, detection of a $\left(\mathrm{R}_{\mathrm{n}}+59\right)^{+}$series instead of the $\left(\mathrm{R}_{\mathrm{n}}+58\right)^{+}$ions in the $0.8-2.8 \mathrm{eV}$ energy range might arise from differences in the experimental set-up. In particular, although dealing with similar center-of-mass energy values, collision rate in the collision cell might be different due to multiple factors. First, data reported in the two studies were obtained using different instruments, and thus different cell length, which could promote multiple collisions to a different extent. Second, the gas pressure (unavailable for our instrument) might also have been very different. Finally, Mayer used an atomic gas (argon) to promote collision while a molecular gas (nitrogen) was employed here, which could induce differences in terms of collisional energy transfer efficiency.

\section{Structure and Formation of the Main Product Ions $(\mathrm{m} / \mathrm{z} 221,295$, and 369)}

High mass accuracy was used here for confident structure assignment and elucidation of oligomer product ion formation, as first demonstrated by Maziarz et al. for PDMS [27]. Elemental composition obtained from accurate mass measurements $\left(m / z\right.$ 221.0838: $\mathrm{C}_{7} \mathrm{H}_{21} \mathrm{O}_{2} \mathrm{Si}_{3}{ }^{+}$, error: $2.7 \mathrm{ppm} ; \mathrm{m} / z$ 295.1021: $\mathrm{C}_{9} \mathrm{H}_{27} \mathrm{O}_{3} \mathrm{Si}_{4}{ }^{+}$, error: $-3.7 \mathrm{ppm} ; \mathrm{m} / \mathrm{z}$ 369.1202: $\mathrm{C}_{11} \mathrm{H}_{33} \mathrm{O}_{4} \mathrm{Si}_{5}{ }^{+}$, error: $\left.-4.9 \mathrm{ppm}\right)$ indicated that these three $\left(\mathrm{R}_{\mathrm{n}}+73\right)^{+}$ions were cationic species which do not contain any nitrogen atoms. Combining this result with the elimination of ammonia observed from the lowest mass precursor ions strongly suggests that product ions observed in MS/MS actually arose from the dissociation of protonated oligomers. This assumption was supported by the fact that $\mathrm{MS}^{3}$ experiments, performed for ammonium adducts and selecting the protonated oligomer as the secondary precursor ion (data not shown), gave rise to spectra displaying the same peak pattern as compared to $\mathrm{MS} / \mathrm{MS}$ of $\left[\mathrm{CH}_{3}-\mathrm{PDMS}_{\mathrm{n}}+\mathrm{NH}_{4}\right]^{+}$. Based on the calculated elemental compositions and the structure of $\mathrm{CH}_{3}-\mathrm{PDMS}$, systematic geometrical optimizations were performed in order to obtain the lowest energetic structures for the three targeted product ions. Various linear forms were tested for each product ion, as well as $\mathrm{DMS}_{n}$ cycles (with $n=2-4$ ), which are further called "n-DMS-containing" rings. A particular class of cycles was also considered, which contain a methylene group instead of an oxygen atom within the ring (and thus further called "C-containing" rings), which first requires a hydroxyl function to be formed upon a proton transfer from a methyl group. The lowest energies associated with the tested conformations as well as examples of these ionic structures are presented in Table 1. For the three studied product ions, linear structures were systematically associated with the highest energy values. In contrast, conformations corresponding to energy minima were all found to exhibit a cyclic structure involving as many DMS units as possible ( 2 in $m / z 221,3$ in $m / z 295$, and 4 in $m / z$ 369) and a trimethylsilyl group substituent on the positively charged oxygen (Scheme 1).

To account for the production of these cyclic ions, protonated oligomers were considered as the actual precursor ions, formed upon loss of ammonia from ammonium adducts, and location of the proton was envisaged on each oxygen atom of the polymeric backbone. As exemplified for the 7-mer in the right-hand side of Scheme 2, location of the proton on the third oxygen atom in $\mathrm{m} / \mathrm{z} 607$ would allow the release of a 386 Da linear monohydroxy-terminated PDMS (further called OH-PDMS) upon cleavage of the $\mathrm{Si}-\mathrm{O}(3)$ bond and the $m / z 221$ product ion to be formed (mechanism indicated by dotted arrows). This cleavage should be considered as the result of a backbiting reaction, depicted 
Table 1. Several conformations of $\mathrm{m} / \mathrm{z} 221$, 295, and 369 evaluated by B3LYP/6-31g(d) optimizations. Linear and DMS-containing ring conformations are illustrated for $\mathrm{m} / \mathrm{z} 221$ while the structure of a C-containing ring is exemplified for $\mathrm{m} / \mathrm{z} 295$

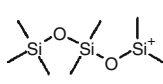

linear form

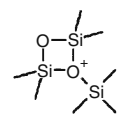

2-DMS containing ring

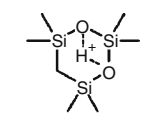

C-containing

6-membered ring

\begin{tabular}{|c|c|c|c|}
\hline $\begin{array}{l}\text { Product } \\
\text { ion }\end{array}$ & Conformation & Energy $(\mathrm{Ha})^{*}$ & $\Delta \mathrm{E}\left(\mathrm{kJ} \cdot \mathrm{mol}^{-1}\right)^{* *}$ \\
\hline \multirow{4}{*}{$\mathrm{m} / \mathrm{z} 221$} & linear & -1298.125727 & +108.9 \\
\hline & 2-DMS-containing ring & -1298.167247 & +0.0 \\
\hline & C-containing 4-membered ring & -1298.145799 & +56.3 \\
\hline & C-containing 6-membered ring & -1298.152148 & +39.6 \\
\hline \multirow{5}{*}{$\mathrm{m} / \mathrm{z} 295$} & linear & -1742.730985 & +166.4 \\
\hline & 2-DMS-containing ring & -1742.787068 & +19.3 \\
\hline & 3-DMS-containing ring & -1742.794441 & $+\mathbf{0 . 0}$ \\
\hline & C-containing 4-membered ring & -1742.765481 & +76.0 \\
\hline & C-containing 6-membered ring & -1742.768926 & +66.9 \\
\hline \multirow{6}{*}{$m / z, 369$} & linear & -2187.379455 & +60.3 \\
\hline & 3-DMS-containing ring & -2187.385663 & +44.0 \\
\hline & 4-DMS-containing ring & -2187.402449 & +0.0 \\
\hline & C-containing 6-membered ring & -2187.379991 & +58.9 \\
\hline & C-containing 8-membered ring & -2187.390281 & +31.9 \\
\hline & C-containing 10-membered ring & -2187.382348 & +52.7 \\
\hline
\end{tabular}

* The Hartree (Ha) is the atomic unit of energy for which the 2006 recommended CODATA value is $4.35974394(22) \cdot 10^{-18} \mathrm{~J}$ [28]." ** Relative to the lowest energetic conformation

in Scheme 2 as a 1,4-electron transfer from a lone pair of $\mathrm{O}$ (1), to create a new silicon-oxygen bond and allow the expected cyclic $\mathrm{m} / \mathrm{z} 221$ ion to be produced. A similar cleavage could also be envisaged for the second $\mathrm{Si}-\mathrm{O}(3)$ bond (mechanism indicated by plain arrows in the right-hand side of Scheme 2), leading to $\mathrm{m} / \mathrm{z} 369$ product ion after the release of a 238 Da linear OH-PDMS. Position of the protonated oxygen within the skeleton would thus determine the size of the product ions: numbering the oxygen atoms from the left-hand side, production of $m / z 73,147,221,295$, 369,443 , and 517 would be, respectively, promoted upon protonation of $\mathrm{O}_{1-7}$ (or $\mathrm{O}_{7-1}$ due to molecular symmetry). The absence of $\mathrm{m} / \mathrm{z} 73$ and 147 in the MS/MS spectrum of the 7-mer precursor ion would suggest a weak stability of these smallest product ions, which cannot adopt a cyclic structure. Moreover, the process which includes a $\mathrm{Si}-\mathrm{O}$ bond cleavage to produce $\left(\mathrm{CH}_{3}\right)_{3} \mathrm{Si}^{+}$at $\mathrm{m} / \mathrm{z} 73$ does not involve the creation of a new $\mathrm{Si}-\mathrm{O}$ bond, due to the location of the protonated oxygen near the end of the chain, hence increasing the energetic cost of this reaction. These assumptions were supported by experiments performed at much higher collision energy (from $\mathrm{E}_{\mathrm{CM}}=1.4 \mathrm{eV}$ for the 7-mer) which allowed these two smallest ions to be observed with low abundance (data not shown). In contrast, the weak intensity of peaks at $m / z 443$ and 517 in Figure 1a suggests a fast dissociation of these two product ions. As depicted in Scheme 2 (left-hand side with plain arrows), the cleavage of the $\mathrm{O}(2)-\mathrm{Si}$ bond upon protonation of the second oxygen atom in the 7-mer would produce $m / z 443$ as a large 5-DMScontaining cyclic ion, together with a $164 \mathrm{Da}$ OH-PDMS. Upon ring opening, a concerted electron transfer would allow the formation of two smaller cyclic species: a 3-DMScontaining neutral and $\mathrm{m} / \mathrm{z} 221$ (as shown in Scheme 2) or a 2-DMS-containing neutral and the cyclic $\mathrm{m} / \mathrm{z} 295$. Similarly, 


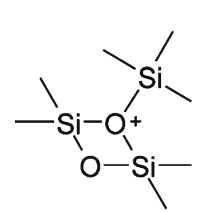

$m / z 221$

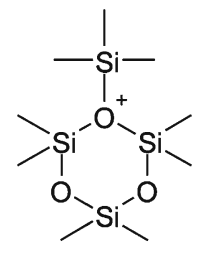

$m / z 295$

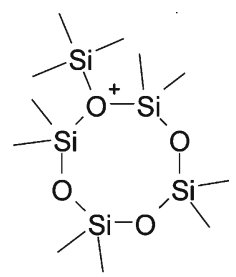

$m / z 369$
Scheme 1.

dissociation of the 6-DMS-containing cyclic $\mathrm{m} / \mathrm{z} 517$ could generate $\mathrm{m} / \mathrm{z} 221,295$, and 369 while eliminating cyclic neutrals consisting of 4,3 , and 2 DMS units, respectively. As a result, production of the three abundant ions of the main series from the ammonium adduct precursor ions can be envisaged to occur in a "two-step" pathway, involving the release of ammonia and of a linear OH-PDMS (steps 1 and 2 in Scheme 2), and/or according to a "three-step" mechanism when loss of ammonia is followed by the production of a large cyclic ion which further dissociates (steps 1, 2', and 3' in Scheme 2).
Energetic costs associated with the proposed mechanisms were assessed by ab initio calculations. Minimal energetic costs were estimated by substracting the intrinsic energies of the products from that of the precursor ion, and some activation barriers were evaluated by a typical Transition State (TS) modelization for each main fragmentation step. It should be noted that, in contrast to the well-defined conformation adopted by ammonium adducts due to the tetrahedric structure of the ammonium cation, selection of the most stable conformation for the protonated molecule implied a more tedious calculation process due to the existence of multiple forms. For the "two-step" pathway depicted in the left-hand part of Figure 3, results from ab initio calculations indicated that the formation of $\mathrm{m} / \mathrm{z} 221$, 295, and 369 from the 7-mer ammonium adduct $(\mathrm{m} / z$ 624) was associated with an amount of energy of, respectively, 186.1, 164.6, and $167.8 \mathrm{~kJ}^{-\mathrm{mol}^{-1}}$. The activation barrier calculated for the $m / z 607 \rightarrow m / z 295$ transition was found to be $64.0 \mathrm{~kJ} . \mathrm{mol}^{-1}$ and further considered as a standard value. In the case of the "three-step" pathway (right-hand part of Figure 3), the amount of energy to produce $\mathrm{m} / \mathrm{z} 221,295$, and 369 from $\mathrm{m} / \mathrm{z} 517$, considered as the intermediate

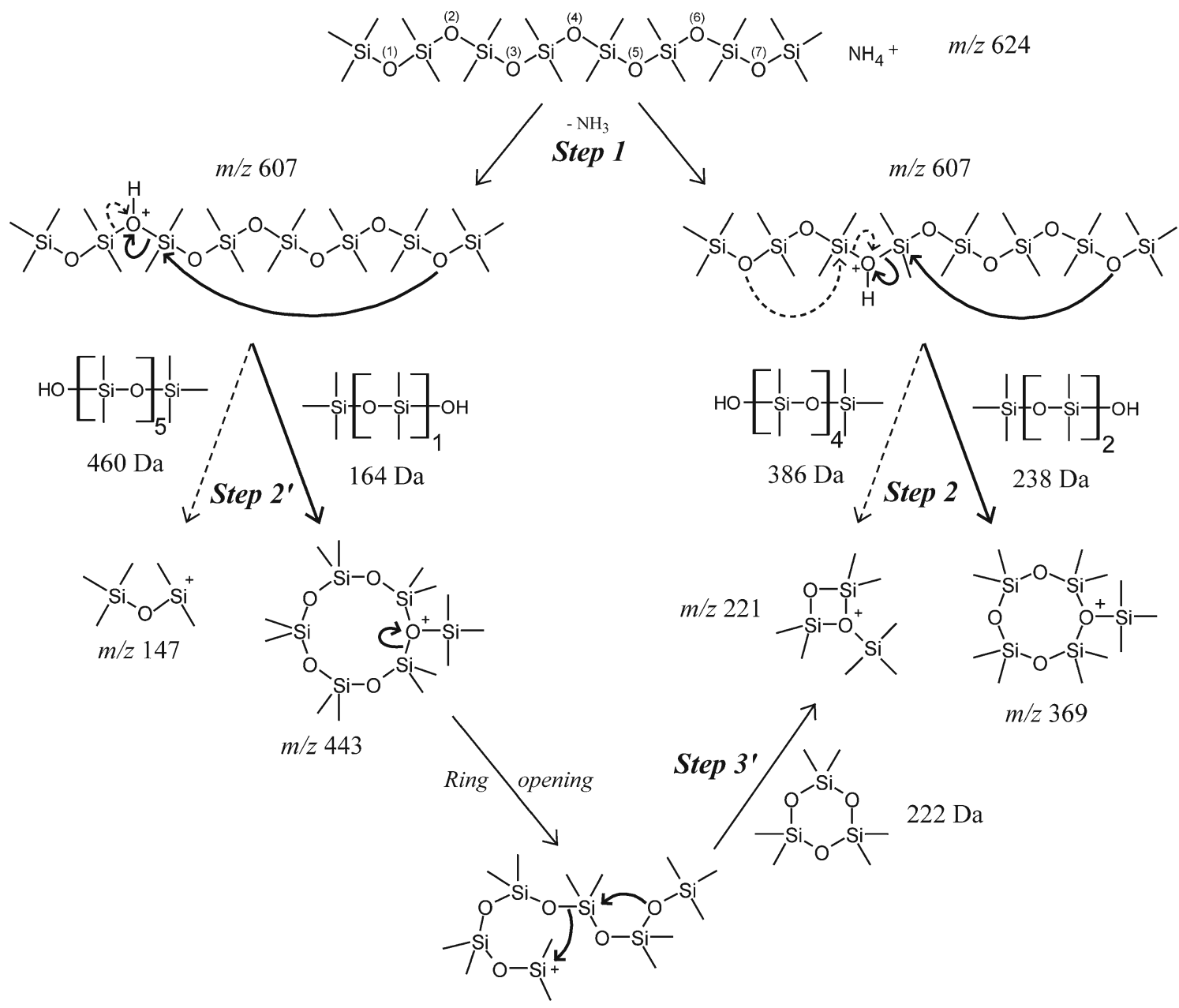

Scheme 2. 


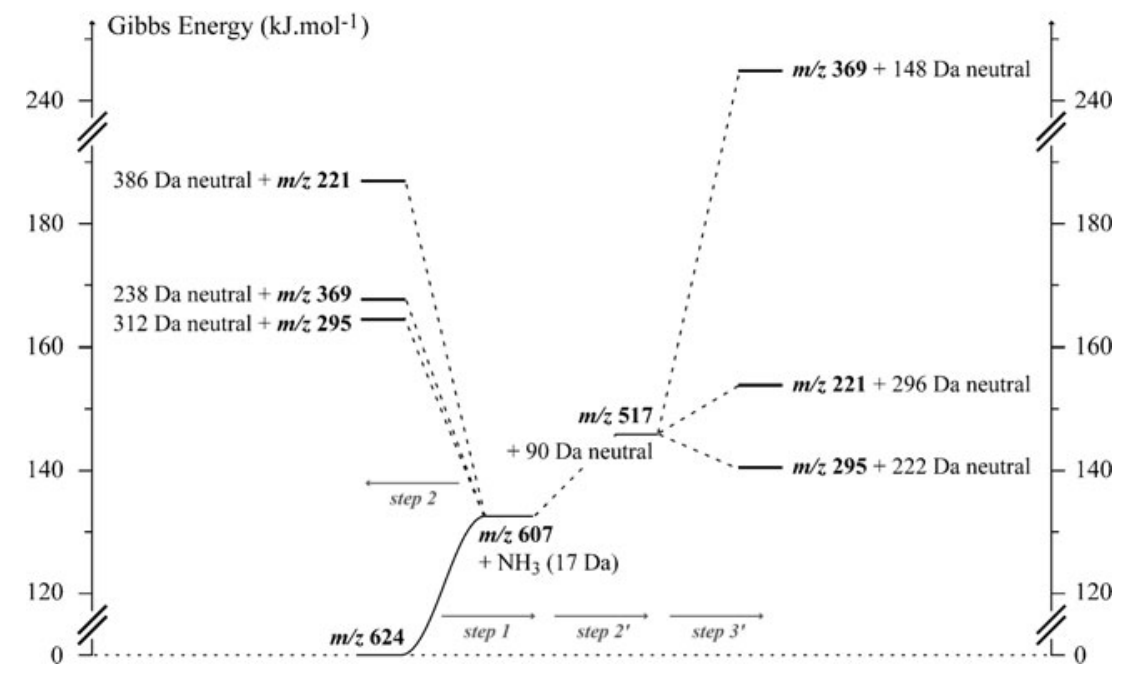

Figure 3. Calculated potential energy surface for the formation of $\left(R_{n}+73\right)^{+}$product ions $(m / z 369$, 295, and 221$)$ from the 7 mer ammonium adduct at $\mathrm{m} / \mathrm{z} 624$, according to a two-step or a three-step dissociation mechanism

product ion formed in step 2', was found to be 153.0, 139.7, and $245.7 \mathrm{~kJ} . \mathrm{mol}^{-1}$, respectively. Values obtained for pathways involving alternative intermediates are reported in Table 2. It should first be noted that those "three-step" pathways which involve the loss of one DMS unit in step 3' after the Si-O bond cleavage (that is, $\mathrm{m} / \mathrm{z} 295 \rightarrow \mathrm{m} / \mathrm{z} 221, \mathrm{~m} / \mathrm{z}$ $369 \rightarrow m / z 295$, and $m / z \quad 443 \rightarrow m / z$ 369) were systematically found to be the most energy demanding, suggesting that such a "depolymerization" process is not favored. Although even the lowest calculated values are much higher than the $88 \mathrm{~kJ} \cdot \mathrm{mol}^{-1}$ activation energy supplied to the precursor ion upon collision ( $0.91 \mathrm{eV}$ center-of-mass frame), the multiple collision regime occurring in the collision cell could account for a final energy (available for dissociation), which is larger than this calculated value. In addition, this result could also suggest that precursor ions were formed with a quite high internal energy in the ESI source [29].

\section{Elimination of a Methane Molecule}

Although the proposed fragmentation pathways would account for the main product ions, they cannot explain the

Table 2. Energetic cost $\left(\mathrm{kJ}^{\mathrm{mol}}{ }^{-1}\right)$ calculated for the production of $\mathrm{m} / \mathrm{z} 369$, 295, and 221 from the $\mathrm{CH}_{3}$-PDMS 7-mer ammonium adduct $(\mathrm{m} / \mathrm{z} 624)$ as a function of the species formed during the second step (step 2 or $2^{\prime}$ ) of the dissociation process described in Scheme 2

\begin{tabular}{lcccc}
\hline Step 2' (or 2) & \multicolumn{5}{c}{ Final product ions } \\
\hline \multicolumn{1}{c}{ Neutral } & Product ion & $m / z 369$ & $m / z 295$ & $m / z ~ 221$ \\
\hline $\mathrm{HO}-\mathrm{Si}\left(\mathrm{CH}_{3}\right)_{3}$ & $m / z 517$ & 245.7 & 139.7 & 153.0 \\
$\mathrm{HO}-\left[\mathrm{Si}\left(\mathrm{CH}_{3}\right)_{2}\right]-\mathrm{Si}\left(\mathrm{CH}_{3}\right)_{3}$ & $m / z 443$ & 384.7 & 251.2 & 160.6 \\
$\mathrm{HO}-\left[\mathrm{Si}\left(\mathrm{CH}_{3}\right)_{2}\right]_{2}-\mathrm{Si}\left(\mathrm{CH}_{3}\right)_{3}$ & $m / z ~ 369$ & 167.8 & 378.3 & 260.0 \\
$\mathrm{HO}-\left[\mathrm{Si}\left(\mathrm{CH}_{3}\right)_{2}\right]_{3}-\mathrm{Si}\left(\mathrm{CH}_{3}\right)_{3}$ & $m / z 295$ & - & 164.6 & 390.0 \\
$\mathrm{HO}-\left[\mathrm{Si}\left(\mathrm{CH}_{3}\right)_{2}\right]_{4}-\mathrm{Si}\left(\mathrm{CH}_{3}\right)_{3}$ & $m / z 221$ & - & - & 186.1 \\
\hline
\end{tabular}

Data associated with the "two-step" mechanism are indicated in italic. formation of $\mathrm{m} / z 591$ generated after elimination of $\mathrm{NH}_{3}$ and $\mathrm{CH}_{4}$ from the 7-mer ammonium adduct (Figure 1a). This reaction was evidenced at low collision energy in all MS/MS spectra of the smallest size precursor ions. Elimination of methane could occur either from the protonated oligomer, after the precursor ion has released ammonia, or in a concerted manner, simultaneously with $\mathrm{NH}_{3}$, from the ammonium adduct. Both cases were envisaged and modelization of transition states involved in these two pathways was performed for the smallest precursor ions (up to $n=5$ ). Results obtained for the calculated transition states clearly show that a concerted elimination of $\mathrm{NH}_{3}$ and $\mathrm{CH}_{4}$ would be more favorable than their sequential losses (Table 3). These data also reveal that the energy requested for the single-stage release of two neutrals from the oligomer ammonium adduct increases with the size of the precursor ion. This suggests ammonium is more tightly bound to increasing size PDMS, considering $n$ ranging from 3 to 5 , consistently with the number of hydrogen bonds formed between the adducted cation and PDMS oxygen atoms. For example, the 3-mer PDMS backbone, able to form two noncovalent hydrogenoxygen bonds with the amonium cation is associated with a

Table 3. Calculated activation energy $\left(\mathrm{kJ}^{\mathrm{m}} \mathrm{mol}^{-1}\right)$ associated with the elimination of ammonia and methane from PDMS ammonium adducts $(n=1-5)$ either in a concerted manner or sequentially

\begin{tabular}{lcc}
\hline & \multicolumn{2}{c}{ Activation Energy $\left(\mathrm{kJ}^{\mathrm{mol}}{ }^{-1}\right)$} \\
\cline { 2 - 3 } & Concerted losses & Sequential losses \\
\cline { 2 - 3 }$n=1$ & +109.3 & +226.6 \\
$n=2$ & +136.9 & $+215.3^{\mathrm{a}}$ \\
$n=3$ & +130.2 & +222.0 \\
$n=4$ & +153.2 & +210.7 \\
$n=5$ & +180.1 & $\mathrm{~b}$ \\
\hline
\end{tabular}

${ }^{\mathrm{a}}$ Methane loss from a methyl group in a DMS unit.

${ }^{\mathrm{b}}$ Not calculated due to undefined transition state involving the protonated 5 -mer. 
(a)

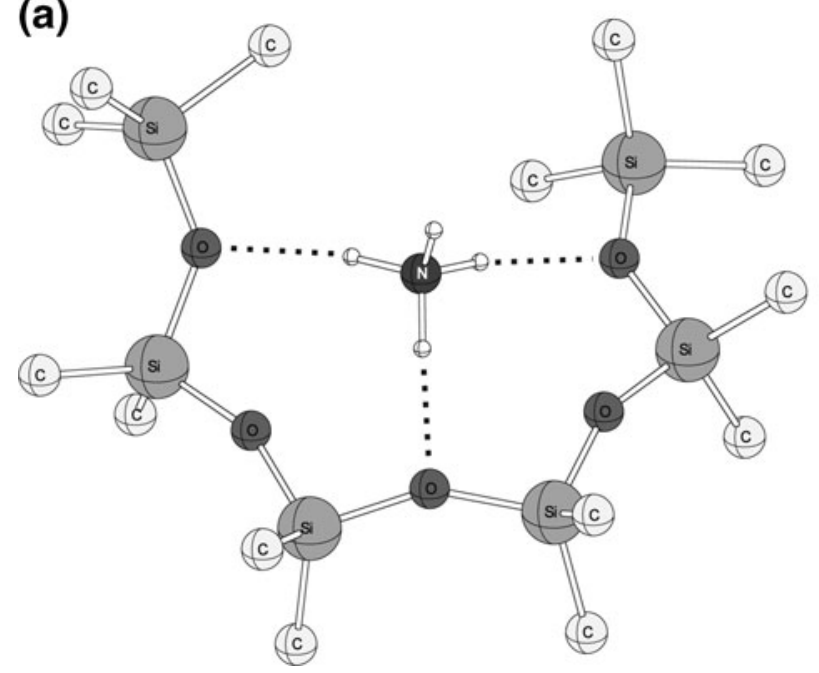

(b)

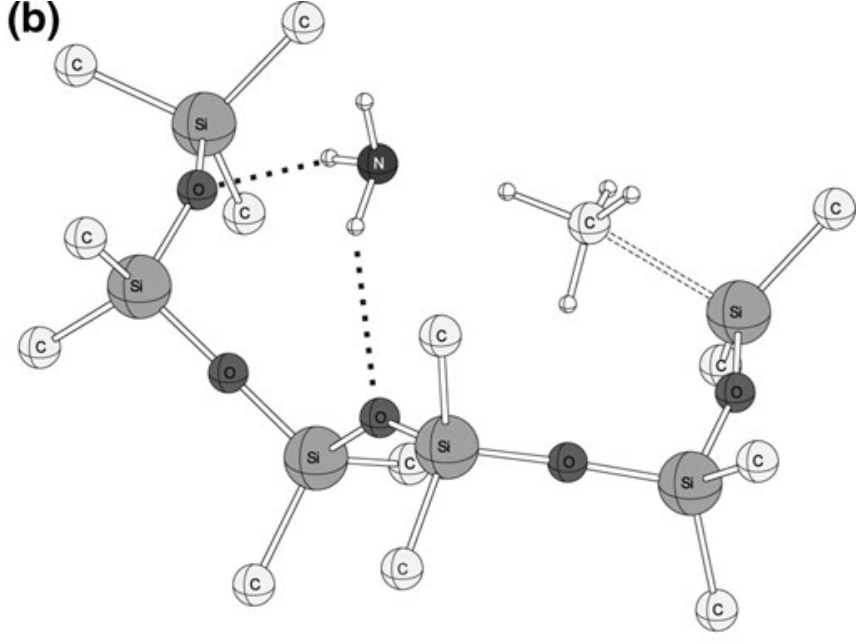

Figure 4. Geometry of the 5-mer ammonium adduct (a) prior activation and (b) once activated to release ammonia and methane in a concerted mechanism, as optimized at the B3LYP/6-31G(d) level

$130.2 \mathrm{~kJ} / \mathrm{mol}$ activation barrier, while a $180.1 \mathrm{~kJ} / \mathrm{mol}$ energy is required for the 5-mer, which readily forms three hydrogen-oxygen bonds (Figure 4a). Since the same number of hydrogen-oxygen bonds, compared with the 5-mer, could be formed while considering the 7 -mer, the same $180.1 \mathrm{~kJ} / \mathrm{mol}$ energy value will be used in a first approximation. Upon adduction by $\mathrm{NH}_{4}^{+}$, the PDMS chain would adopt a conformation to wrap the cation, all methyl groups but the terminal ones pointing towards the outside and hence not interacting with ammonium protons (Figure 4a). As a result, while considering the concerted pathway, release of a methane molecule would exclusively proceed from an endof-chain methyl group. In contrast, in the sequential loss scenario, which first involves the production of a protonated
PDMS, release of methane can occur from any methyl group in the chain, and initial location of this methyl group was not shown to greatly influence activation energy of this dissociation reaction. Indeed, in the case of the 2-mer ammonium adduct, activation energy for the sequential loss of $\mathrm{NH}_{3}$ and $\mathrm{CH}_{4}$ was calculated by considering a methyl from a DMS unit and was found to be $215.3 \mathrm{~kJ}^{\mathrm{mol}}{ }^{-1}$, which compares well with values obtained from other precursor ions when using a leaving methyl moiety from an end-group (Table 3). The transition state calculated for the release of $\mathrm{NH}_{3}$ and $\mathrm{CH}_{4}$ from the 5-mer ammonium adduct is depicted in Figure 4b: methane is formed upon protonation of a terminal methyl group, while $\mathrm{NH}_{3}$ still interacts via hydrogen bonds with two oxygen atoms of the polymeric

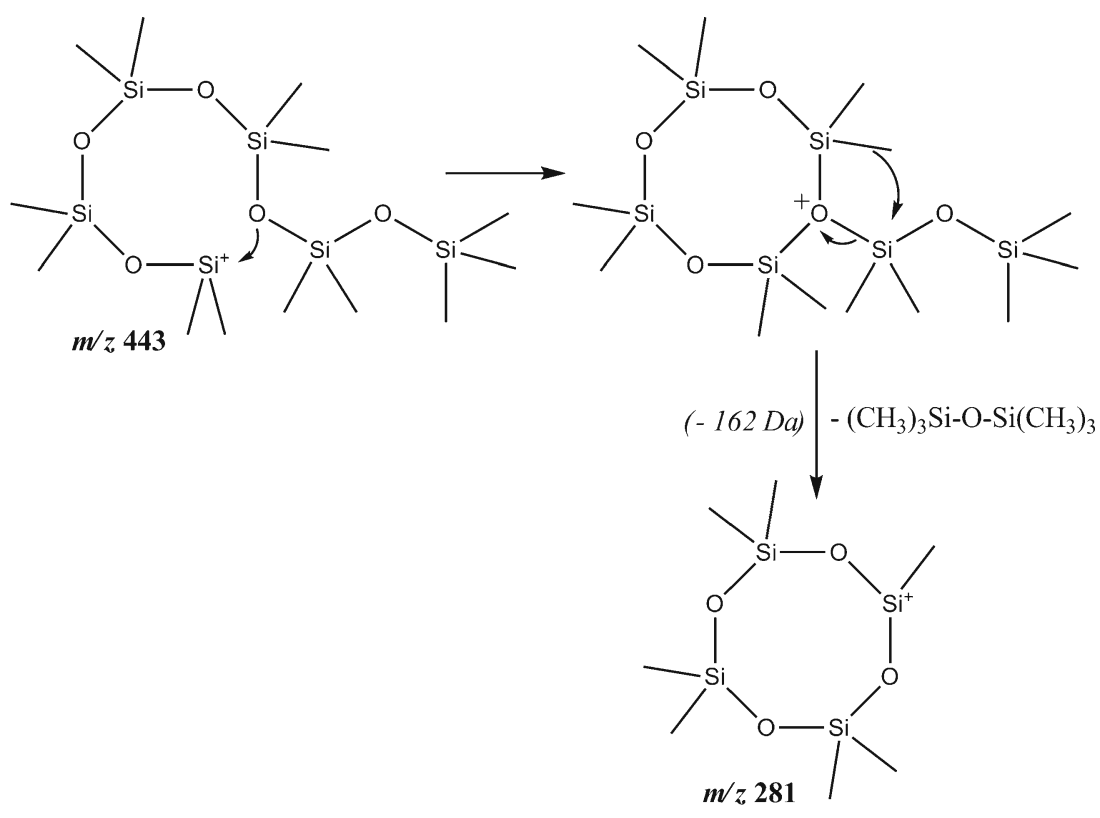

Scheme 3. 
backbone. The proposed concerted mechanism, together with increasing activation barriers as a function of polymerization degree, would account for the lack of methane elimination from large precursor ions since the probability of ammonium interacting with one of the terminal methyl groups rapidly decreases as the size of the PDMS chain increases.

Product ions formed upon a concerted release of $\mathrm{NH}_{3}$ and $\mathrm{CH}_{4}$ would carry a positive charge located on an end-ofchain silicon atom, that is, the case described after ring opening of the ionic structure generated in step $2^{\prime}$ of Scheme 2. As a result, so-formed product ions would either adopt a more stable cyclic conformation via electron transfer from an oxygen lone pair or release a cyclic PDMS neutral as in step 3' of Scheme 2, depending on their size. In the case of the 7-mer ammonium adduct at $\mathrm{m} / \mathrm{z} 624$, the activation barrier for production of $\mathrm{m} / \mathrm{z} 591$ after simultaneous losses of ammonia and methane was approximated to $180 \mathrm{~kJ} \cdot \mathrm{mol}^{-1}$ (vide supra). This $m / z 591$ product ion would further dissociate, according to mechanism depicted in Scheme 2, to yield the three main product ions of the $\left(\mathrm{R}_{\mathrm{n}}+73\right)^{+}$series via reactions, which were all found to be exothermic $\left(\mathrm{m} / z\right.$ 591 $\rightarrow \mathrm{m} / z$ 221: $-9.6 \mathrm{~kJ} . \mathrm{mol}^{-1}$; $\mathrm{m} / \mathrm{z} 591 \rightarrow \mathrm{m} / \mathrm{z}$ 295: $-21.6 \mathrm{~kJ} \cdot \mathrm{mol}^{-1}$, and $\mathrm{m} / \mathrm{z} \quad 591 \rightarrow \mathrm{m} / \mathrm{z}$ 369: $-23.8 \mathrm{~kJ} \cdot \mathrm{mol}^{-1}$ ).

\section{Structure and Formation of the Secondary Product Ions ( $\mathrm{m} / \mathrm{z} 207,281$, and 355)}

From the breakdown curves shown in Figure 2, the additional ion series $\left(\mathrm{R}_{\mathrm{n}}+59\right)^{+}$was suspected to arise from the dissociation of the main $\left(\mathrm{R}_{\mathrm{n}}+73\right)^{+}$series. This assumption was supported by $\mathrm{MS}^{3}$ experiments, selecting small oligomer ammonium adducts as primary precursor ions to produce a large range of product ions in the main series. These experiments showed $\mathrm{m} / \mathrm{z} 207,281$, and 355 were formed upon activation of members of the $\left(\mathrm{R}_{\mathrm{n}}+73\right)^{+}$ series selected as secondary precursor ions. For example, $\mathrm{m} / \mathrm{z}$ 281.1 was detected as a product ion of $\left(\mathrm{R}_{5}+73\right)^{+}$at $\mathrm{m} / \mathrm{z}$ 443.2, arising from the dissociation of the 9-mer ammonium adduct. It should be noted, however, that the base peak in this $\mathrm{MS}^{3}$ spectrum (data not shown) was observed at $\mathrm{m} / \mathrm{z}$ 221.1, while relative abundance measured for $\mathrm{m} / \mathrm{z} 281.1$ was only $9.4 \%$.

The three $\left(\mathrm{R}_{\mathrm{n}}+59\right)^{+}$ions could be produced via two main reactions from $\left(\mathrm{R}_{\mathrm{n}}+73\right)^{+}$ions, consisting of the release of $88 \mathrm{Da}$ (tetramethylsilane) or $162 \mathrm{Da}$ (hexamethyldisiloxane HMDSO) neutrals. Elimination of tetramethylsilane would proceed via a methyl transfer $[1,14]$ from a $\mathrm{Si}$ atom involved in DMS ring to the neighbored trimethylsilyl pendant group (Supplemental Figure S2). A similar mechanism could be envisaged to account for loss of a $162 \mathrm{Da}$ neutral, providing a $-\mathrm{Si}\left(\mathrm{CH}_{3}\right)_{2}-\mathrm{O}-\mathrm{Si}\left(\mathrm{CH}_{3}\right)_{3}$ pendant group is connected to a PDMS ring after rearrangement following the ring opening prior to step $3^{\prime}$ in Scheme 2. Such a mechanism is depicted in Scheme 3 for $\mathrm{m} / \mathrm{z} 443$ as formed in step $2^{\prime}$ of Scheme 2. Upon ring opening, a 1,8- electron transfer has first to be envisaged to generate an eight-member DMS ring bearing the targeted pendant group, further released as a $162 \mathrm{Da}$ neutral upon methyl transfer. However, such a mechanism would poorly compete with the reaction yielding $\mathrm{m} / \mathrm{z} 221$ from $\mathrm{m} / \mathrm{z} 443$ in Scheme 2, as clearly illustrated by relative abundance of $\mathrm{m} / \mathrm{z} 221$ and 281 in $\mathrm{MS}^{3}$ experiments (vide supra).

\section{Conclusion}

In contrast to alkali adducts, dissociation of $\mathrm{CH}_{3}$-PDMS ammonium adducts was shown to always give rise to the same three main product ions, regardless of the size of the precursor ion. Based on ab initio calculation, particularly stable cyclic structures could be found for these product ions, and proposed reaction mechanisms could account for the observed unimolecular fragmentation, information regarding the size of the precursor ion being mainly contained in the released neutrals. It could be concluded that this MS/MS behavior is characteristic of linear trimethylsilyl-terminated PDMS oligomers, in contrast to some CID data obtained in a recent study of a PDMS film resulting from plasma polymerization [30], which would reveal multiple ramifications of the polymer backbone. MS/ MS of ammonium adducts of PDMS oligomers bearing alternative end-groups will be scrutinized in a forthcoming work to study the influence of the end-group on their dissociation pattern.

\section{Acknowledgments}

L.C. acknowledges support from Spectropole, the Analytical Facility of Aix-Marseille University, by allowing a special access to the instruments purchased with European Funding (FEDER OBJ2142-3341). The authors gratefully acknowledge financial support by the Luxembourg Research Funding Association FNR (Fond National de la Recherche).

\section{References}

1. Wesdemiotis, C., Solak, N., Polce, M.J., Dabney, D.E., Chaicharoen, K., Katzenmeyer, B.C.: Fragmentation pathways of polymer ions. Mass Spectrom. Rev. (2010), in press. doi:10.1002/mas.20282

2. Giordanengo, R., Viel, S., Allard-Breton, B., Thevand, A., Charles, L.: Positive mode electrospray tandem mass spectrometry of poly(Methacrylic acid) oligomers. Rapid Commun. Mass Spectrom. 23, 15571562 (2009)

3. Giordanengo, R., Viel, S., Allard-Breton, B., Thevand, A., Charles, L.: Tandem mass spectrometry of poly(Methacrylic acid) oligomers produced by negative mode electrospray ionization. J. Am. Soc. Mass Spectrom. 20, 25-33 (2009)

4. Alhazmi, A.M., Mayer, P.M.: Protonating polymer oligomers in the gas phase to change fragmentation pathways. J. Am. Soc. Mass Spectrom. 20, 60-66 (2009)

5. Jackson, A.T., Yates, H.T., Scrivens, J.H., Green, M.R., Bateman, R.H.: Utilizing matrix-assisted laser desorption/ionization-collision induced dissociation for the generation of structural information from poly(Alkyl Methacrylate)s. J. Am. Soc. Mass Spectrom. 8, 1206-1213 (1997)

6. Borman, C.D., Jackson, A.T., Bunn, A., Cutter, A.L., Irvine, D.J.: Evidence for the low thermal stability of poly(methyl methacrylate) 
polymer produced by atom transfer radical polymerisation. Polymer. 41, 6015-6020 (2000)

7. Jackson, A.T., Bunn, A., Chisholm, M.S.: Utilising matrix-assisted laser desorption/ionization techniques for the generation of structural information from different end-group functionalised poly(Methyl Methacrylate)s. Polymer. 49, 5254-5261 (2008)

8. Baumgaertel, A., Becer, C.R., Gottschaldt, M., Schubert, U.S.: MALDITOF MS coupled with collision-induced dissociation (CID) measurements of poly(Methyl Methacrylate). Macromol. Rapid Commun. 29, 1309-1315 (2008)

9. Lattimer, R.P.: Tandem mass-spectrometry of lithium-attachment ions from polyglycols. J. Am. Soc. Mass Spectrom. 3, 225-234 (1992)

10. Lattimer, R.P.: Tandem mass-spectrometry of poly(Ethylene Glycol) lithium-attachment ions. J. Am. Soc. Mass Spectrom. 5, 1072-1080 (1994)

11. Selby, T.L., Wesdemiotis, C., Lattimer, R.P.: Dissociation characteristics of $\mathrm{M}+\mathrm{X}(+)$ ions $(\mathrm{X}=\mathrm{H}, \mathrm{Li}, \mathrm{K})$ from linear and cyclic polyglycols. J. Am. Soc. Mass Spectrom. 5, 1081-1092 (1994)

12. Hoteling, A.J., Kawaoka, K., Goodberlet, M.C., Yu, W.M., Owens, K. G.: Optimization of matrix-assisted laser desorption/ionization time-offlight collision-induced dissociation using poly(Ethylene Glycol). Rapid Commun. Mass Spectrom. 17, 1671-1676 (2003)

13. Jackson, A.T., Green, M.R., Bateman, R.H.: Generation of end-group information from polyethers by matrix-assisted laser desorption/ionization collision-induced dissociation mass spectrometry. Rapid Commun. Mass Spectrom. 20, 3542-3550 (2006)

14. Renaud, J., Alhazmi, A.M., Mayer, P.M.: Comparing the fragmentation chemistry of gas-phase adducts of poly(Dimethylsiloxane) oligomers with metal and organic ions. Can. J. Chem. 87, 453-459 (2009)

15. Chen, H.: Endgroup-assisted siloxane bond cleavage in the gas phase. $J$. Am. Soc. Mass Spectrom. 14, 1039-1048 (2003)

16. Charles, L.: Influence of internal standard charge state on the accuracy of mass measurements in orthogonal acceleration-time of flight mass spectrometers. Rapid Commun. Mass Spectrom. 22, 151-155 (2008)

17. Frisch, M.J., Trucks, G.W., Schlegel, H.B., Scuseria, G.E., Robb, M.A., Cheeseman, J.R., Montgomery, J.A. Jr., Vreven, T., Kudin, K.N., Burant, J.C., Millam, J.M., Iyengar, S.S., Tomasi, J., Barone, V., Mennucci, B., Cossi, M., Scalmani, G., Rega, N., Petersson, G.A., Nakatsuji, H., Hada, M., Ehara, M., Toyota, K., Fukuda, R., Hasegawa, J., Ishida, M., Nakajima, T., Honda, Y., Kitao, O., Nakai, H., Klene, M., Li, X., Knox, J.E., Hratchian, H.P., Cross, J.B., Adamo, C., Jaramillo, J., Gomperts, R., Stratmann, R.E., Yazyev, O., Austin, A.J., Cammi, R., Pomelli, C., Ochterski, J.W., Ayala, P.Y., Morokuma, K., Voth, G.A., Salvador, P., Dannenberg, J.J., Zakrzewski, V.G., Dapprich, S., Daniels, A. D., Strain, M.C., Farkas, O., Malick, D.K., Rabuck, A.D., Raghavachari, K., Foresman, J.B., Ortiz, J.V., Cui, Q., Baboul, A.G., Clifford, S., Ciolowski, J., Stefanov, B.B., Liu, G., Liashenko, A., Piskorz, P.,
Komaromi, I., Martin, R.L., Fox, D.J., Keith, T., Al-Laham, M.A., Peng, C.Y., Nanayakkara, A., Challacombe, M., Gill, P.M.W., Johnson, B., Chen, W., Wong, M.W., Gonzalez, C., Pople, J.A.: Gaussian 03, C.02; Gaussian Inc.: Wallingford, CT, 2004.

18. Becke, A.D.: Density-functional thermochemistry. 3. The role of exact exchange. J. Chem. Phys. 98, 5648-5652 (1993)

19. Lee, C.T., Yang, W.T., Parr, R.G.: Development of the colle-salvetti correlation-energy formula into a functional of the electron-density. Phys. Rev. B Condens. Matter 37, 785-789 (1988)

20. De Proft, F., Tielens, F., Geerlings, P.: Performance and basis set dependence of density functional theory dipole and quadrupole moments. J. Mol. Struct. THEOCHEM 506, 1-8 (2000)

21. de Jong, G.T., Bickelhaupt, F.M.: Oxidative addition of the fluoromethane $\mathrm{C}-\mathrm{F}$ bond to $\mathrm{Pd}$. An ab initio benchmark and DFT validation study. J. Phys. Chem. A 109, 9685-9699 (2005)

22. de Jong, G.T., Geerke, D.P., Diefenbach, A., Bickelhaupt, F.M.: DFT benchmark study for the oxidative addition of $\mathrm{CH} 4$ to Pd. Performance of various density functionals. Chem. Phys. 313, 261-270 (2005)

23. Hariharan, P.C., Pople, J.A.: The influence of polarization functions on molecular orbital hydrogenation energies. Theor. Chim. Acta 28, 213222 (1972)

24. Francl, M.M., Pietro, W.J., Hehre, W.J., Binkley, J.S., Gordon, M.S., Defrees, D.J., Pople, J.A.: Self-consistent molecular-orbital methods.23. a Polarization-type basis set for 2nd-row elements. J. Chem. Phys. 77, 3654-3665 (1982)

25. Krishnan, R., Binkley, J.S., Seeger, R., Pople, J.A.: Self-consistent molecular-orbital methods. 20. Basis set for correlated wave-functions. J. Chem. Phys. 72, 650-654 (1980)

26. Blaudeau, J.P., McGrath, M.P., Curtiss, L.A., Radom, L.: Extension of gaussian-2 (G2) theory to molecules containing third-row atoms $\mathrm{K}$ and Ca. J. Chem. Phys. 107, 5016-5021 (1997)

27. Maziarz, E.P., Baker, G.A., Wood, T.D.: Capitalizing on the high mass accuracy of electrospray ionization fourier transform mass spectrometry for synthetic polymer characterization: a detailed investigation of poly(Dimethylsiloxane). Macromolecules 32, 4411-4418 (1999)

28. Mohr, P.J., Taylor, B.N., Newell, D.B.: CODATA recommended values of the fundamental physical constants: 2006. Rev. Mod. Phys. 80, 633730 (2008)

29. Gabelica, V., De Pauw, E.: Internal energy and fragmentation of ions produced in electrospray sources. Mass Spectrom. Rev. 24, 566-587 (2005)

30. Bour, J., Charles, L., Petersen, J., Michel, M., Bardon, J., Ruch, D.: Insights in molecular structure of organosilicon plasma polymer produced by means of atmospheric pressure dielectric barrier discharge process. Plasma Processes Polym. 7, 687-694 (2010) 